\title{
PROTOCOL
}

\section{Quality of life in stroke survivor-caregiver dyads: a new conceptual framework and longitudinal study protocol}

\author{
Serenella Savini, Harleah G. Buck, Victoria Vaughan Dickson, Silvio Simeone, Gianluca Pucciarelli, \\ Roberta Fida, Maria Matarese, Rosaria Alvaro \& Ercole Vellone
}

Accepted for publication 9 August 2014

\section{Correspondence to E. Vellone: \\ e-mail: ercole.vellone@uniroma2.it \\ Serenella Savini PhD RN \\ School of Nursing, Sapienza University, \\ Bracciano (RM), Italy \\ Harleah G. Buck PhD RN CHPN \\ The Pennsylvania State University College of Nursing, University Park, Pennsylvania, USA}

Victoria Vaughan Dickson PhD RN FAHA New York University College of Nursing, New York, USA

Silvio Simeone MSN RN

University of Rome Tor Vergata, Rome, Italy

Gianluca Pucciarelli MSN RN University of Rome Tor Vergata, Rome, Italy

Roberta Fida $\mathrm{PhD}$

Sapienza University, Rome, Italy

Maria Matarese MSN RN

University Campus Bio-Medico, Rome, Italy

Rosaria Alvaro MSN RN

University of Rome Tor Vergata, Rome, Italy

Ercole Vellone MSN RN

University of Rome Tor Vergata, Rome, Italy
SAVINI S., BUCK H.G., DICKSON V.V., SIMEONE S., PUCCIARELLI G., FIDA R., MATARESE M., ALVARO R. \& VELLONE E. (2015) Quality of life in stroke survivor-caregiver dyads: a new conceptual framework and longitudinal study protocol. Journal of Advanced Nursing 71(3), 676-687. doi: 10.1111/jan.12524

\section{Abstract}

Aim. To describe a new conceptual framework and the research protocol of a study designed to examine the quality of life in stroke survivor-caregiver dyads.

Background. Stroke has a significant impact on the patient-caregiver dyad. Few studies have been guided by a specific conceptual framework which considers the interactions among pre-existing situations prior to stroke, the new situation caused by the stroke and the moderating effects of environmental and caregiverrelated variables.

Design. Longitudinal study.

Methods. A sample of stroke survivor-caregiver dyads will be enrolled at patient discharge from rehabilitation hospitals and will be surveyed every 3 months for 1-year. Hypotheses generated from the conceptual framework will test predictors, mediators and moderators of stroke survivor and caregiver quality of life from the pre-existing situation prior to the stroke, the new situation mediation poststroke and situation moderators. The study is supported by a grant from the Centre of Excellence for Nursing Scholarship, Rome, December 2013.

Discussion. This study seeks to identify variables in the pre-existing situation prior to the stroke (e.g. living condition), the new situation mediation poststroke (e.g. type of stroke and caregiver burden) as well as situation moderators (e.g. social support) that influence stroke survivor-caregiver dyad's quality of life across the stroke trajectory. Also, the study will inform clinical practice and research by identifying variables that are potentially modifiable and therefore amenable to intervention. The proposed framework will also be helpful for future research focused on stroke survivor-caregiver dyads.

Keywords: conceptual framework, dyad, longitudinal study, nursing, quality of life, stroke, stroke caregiver, stroke survivor, study protocol 


\section{Why is this research needed?}

- Poor quality of life in stroke caregivers is associated with patient rehospitalization and increased healthcare costs. The study introduces a new theoretically and empirically derived conceptual framework, which predicts quality of life in stroke survivor-caregiver dyad's quality of life.

- The conceptual framework will be tested in a proposed longitudinal study to examine the predictive power of the framework in stroke survivor-caregivers dyad's quality of life at baseline and 3, 6, 9 and 12 months after patients are discharged home.

- The results of this study will also potentially provide evidence for the mechanism by which selected predictors, mediators and moderators affect stroke survivor-caregiver dyads' quality of life to inform future interventions to improve their quality of life.

\section{Introduction}

Stroke is a leading cause of death and disability among adults in developed countries (Feigin et al. 2014). International studies show a prevalence of stroke from $6 \cdot 2-13.9 \%$ in people over 60 years of age (Go et al. 2014) and an incidence per year of 141.3 new cases in men and 94.6 in women per 100.000 among people aged between 6584 years (European Registers of Stroke I. et al. 2009).

Stroke has a significant impact on stroke survivor-caregiver dyads' quality of life (QOL) (Cecil et al. 2013, Simeone et al. 2014). Approximately 35\% of stroke survivors have severe disabilities and limitations in activities of daily living; 30\% suffer from depression and cognitive impairment (Chen et al. 2010), all factors known to influence QOL negatively. In addition, stroke has a significant impact on caregivers who often exhibit low QOL, high stress, burden, anxiety and depression (Nir et al. 2009). Numerous studies have shown that poor QOL in stroke caregivers is associated with the rehospitalization of stroke survivors and increased health costs (Perrin et al. 2009, Garcia-Perez et al. 2011).

Several studies have been conducted on QOL both for stroke survivors and stroke caregivers (Green \& King 2010, McPherson et al. 2011), but most of these have used a crosssectional design limiting the ability to understand the process of the patient's recovery and caregiver's experience, which can change over time (Godwin et al. 2013a,b). Also, few longitudinal studies conducted both on stroke survivors and their caregivers have considered the mechanisms of the interactions among pre-existing situation prior to the stroke, the new situation caused by the stroke and the moderating effects of environmental- and caregiver-related variables. This significant gap in the science may be a result of the limited theoretical work conducted in this population. Further research is needed to examine the patient and caregiver perspective on the stroke experience and the resulting QOL outcomes in these stroke survivor and caregiver dyads.

\section{Conceptual framework and background}

The conceptual framework presented in Figure 1 will guide this study and was adapted from McCubbin et al. (1983) and Lazarus and Folkman (1984) conceptual models. The conceptual framework of the study was also informed by the extant literature. This literature suggests that QOL in stroke survivor-caregiver dyads is influenced by the preexisting situation prior to the stroke, the mediation of the new situation poststroke and moderators such as environmental and caregiver-related variables (e.g. continuity of stroke rehabilitation and social support) (Carod-Artal 2012, Ellis et al. 2013). The conceptual framework suggests that the pre-existing situation prior to stroke has a direct influence on the new situation poststroke and an indirect influence on the QOL of survivor-caregiver dyads (the outcome of the model). The dyad's pre-existing situation refers to the individual characteristics of stroke survivors and their caregivers as well as the characteristics of their relationship. The new situation is the stroke and related caregiving and this is posited to mediate the relationship between the pre-existing situation and the dyad's QOL. Several situational moderators, such as the amount of social and rehabilitative support available, are hypothesized to influence the relationship between the new situation and the outcomes. As illustrated in the model, QOL outcomes are conceptualized as dyadic outcomes; hence, it is hypothesized that the QOL of stroke survivors and caregivers is interdependent and each influences the other (Baumann et al. 2012). We will discuss each concept further in the following sections.

\section{Pre-existing situation prior to stroke}

According to the current literature, the pre-existing situations of stroke survivors and their caregivers, including such elements as socio-demographics, living conditions, the affective relationship between the stroke survivor and the caregiver and the stroke survivor's comorbidity, can all influence dyad QOL (Baumann et al. 2012).

In stroke survivors, socio-demographic factors that have been found to influence QOL are age, gender, marital status and education. Older age in stroke survivors has been 


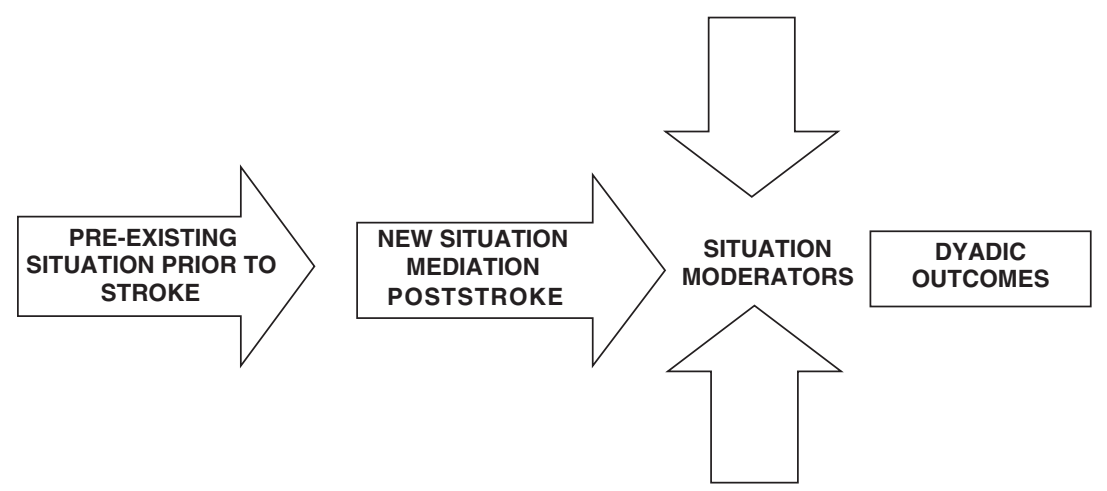

Figure 1 The conceptual framework of the study.

found to be associated with lower physical QOL, but higher emotional QOL (Baumann et al. 2012). Baumann et al. (2012) reported that female stroke survivors exhibited greater life satisfaction and mental health than male survivors and that life satisfaction was positively correlated with five QOL dimensions: feelings, sleep, emotion, cognition and pain (Baumann et al. 2012). The same authors have also found that QOL is better in married stroke survivors than in those who are separated, divorced or widowed (Baumann et al. 2012). These findings suggest that the emotional and social aspects of living in partnership are important to subjective well-being. Education is another variable that influences QOL in stroke survivors as it has been found that stroke survivors who are more educated have better coping and better global QOL than those who are less educated (Dayapoglu \& Tan 2010).

Similarly for caregivers, the socio-demographic characteristics that can influence QOL include gender, marital status and whether they are living with the patient (Klinedinst et al. 2009). Several studies (Aprile et al. 2008, Brajkovic et al. 2009) have found increased levels of burden and depression among female caregivers compared with male caregivers. In particular, female caregivers were less likely to ask for help and support in patient care and spent more time on caregiving than males even though having a female caregiver was associated with a better QOL for the stroke survivor (Klinedinst et al. 2009). Female caregivers who consistently scored low on mental QOL were found to be more likely to be unemployed and reported higher burden scores and a lower overall QOL (White et al. 2003). Stroke caregiver's QOL has also been found to be influenced by education (Brajkovic et al. 2009).

Living conditions influence the QOL for both stroke survivors and their caregivers. Stroke survivors and caregivers living in urban areas reported better QOL than those living in rural areas, presumably because they had easier access to social and medical support (Dayapoglu \& Tan 2010, Baumann et al. 2012).

Another characteristic that can affect QOL for caregivers and survivors is their relationship. Several authors (Dayapoglu \& Tan 2010, Delcourt et al. 2011) have shown that married stroke survivors and stroke caregivers have a better QOL than those who are unmarried, probably due to better support. Other authors found that mutuality in survivor and caregiver dyad is a positive predictor of their QOL (Ostwald et al. 2009b).

Comorbidity in the stroke survivor is associated with both the stroke survivor's and his/her caregiver's QOL. More comorbid conditions in survivors decrease their QOL and increase mortality, especially in females (Icks et al. 2012). Conversely, quality of life, well-being and functional ability have been shown to be higher in stroke survivors with no comorbidities especially for male stroke survivors, those who are currently employed and those with higher education levels. In addition, comorbid conditions have a negative impact on the outcomes of patient rehabilitation and social reintegration and increase the caregiver burden (Van Puymbroeck et al. 2008, Ellis et al. 2013).

\section{New situation mediation poststroke}

A stroke is indeed both a new and a sudden situation for the stroke survivor-caregiver dyad. Two groups of variables are associated with this new situation: stroke-related variables and caregiving-related variables. Stroke-related variables can be categorized as type and site of stroke, physical functioning, mood state (anxiety and depression) and stroke complications (e.g. falls). The caregiving-related variables are the burden, anxiety and depression, expenses for care, caregiving duration and time available for caregiving. 
The type of stroke has a varying impact on stroke survivor QOL (Cadilhac et al. 2010). For example, stroke caused by an intra-cerebral haemorrhage has a deeper impact on QOL than an ischaemia (Cadilhac et al. 2010). Also, the site of the brain lesion can have an influence on QOL. It is known that patients with right hemispherical lesions have better functional status than those with a lesion in the left hemisphere of the brain (Dayapoglu \& Tan 2010).

Physical functioning is another stroke-related variable influencing stroke survivor QOL. Stroke can limit the activities of daily life (ADL) (Rouillard et al. 2012), which can then reduce participation in work, household responsibilities and social and leisure activities. As a result, there may be role changes, social isolation and lower emotional and mental QOL (Rouillard et al. 2012).

Depression and anxiety affect the stroke survivor's outcome and recovery including QOL (Kouwenhoven et al. 2011). High levels of depression increase the risk of death by more than $10 \%$ (Raju et al. 2010) and may cause poorer adherence to treatment (Kronish et al. 2012) and less autonomy in self-care activities (Korpershoek et al. 2011). As a consequence of a stroke, survivors may also experience high levels of anxiety especially during the first weeks following the stroke (D'Aniello et al. 2014).

Stroke is associated with numerous complications that can influence QOL. Falls are very common among stroke rehabilitation patients. It has been estimated that between 14-65\% of stroke survivors fall at least once during hospitalization (Weerdesteyn et al. 2008) and up to $73 \%$ of patients fall during the first 6 months after discharge (Batchelor et al. 2010). Falls adversely affect the stroke survivors' QOL and increase their risk of morbidity and mortality (Wagner et al. 2009).

Stroke caregiving is particularly burdensome for women who experience depression, anxiety and burden (CarodArtal et al. 2009, Vincent et al. 2009). Often these variables are interrelated. Burden in female caregivers increases with the length of time spent in caregiving. Caregiving burden is exacerbated by the lack of preparation for caregiving (Visser-Meily et al. 2005). Studies (Visser-Meily et al. 2005) have shown that caregiver burden is related to a caregiver's depressive symptoms, to the survivor's activities of daily living (ADL) and to disharmony in the relationship with the stroke survivor. Caregiver burden influences caregiver QOL and may change over time, but the change patterns are still unclear in the literature (Vincent et al. 2009).

Literature has shown that decreased psychological QOL in caregivers is correlated with the number of hours spent in caregiving. That is because an increased level of involvement or the number of hours spent in caregiving often results in lower participation in social activities, as well as increased frustration and depression (Lurbe-Puerto et al. 2012).

After a stroke, caregivers may experience many direct and indirect expenses due to caregiving: they may need to buy equipment for patient care or they may have to give up work. It has been shown that additional expenses worsen stroke caregiver QOL (Sreedharan et al. 2013).

Caregiving duration is another caregiving-related variable that influences caregiver QOL. In general, caregiver QOL is lower at the beginning of the caregiving experience, but tends to improve over time (Nir et al. 2009). However, stroke caregiver QOL is significantly lower than in the general population (Visser-Meily et al. 2008).

\section{Situation moderators}

Moderators are variables that affect the association between an independent and a dependent variable. Specifically, a moderator is an independent variable that affects the strength, either by inhibiting or enhancing and/or directing the association between another independent variable and an outcome variable (Levy et al. 2011). One group of moderators that can affect the QOL outcomes is included in the conceptual framework of this study: namely, environmentaland caregiver-related variables. These variables include social support, the continuity of stroke rehabilitation and caregiving preparation.

In the environmental- and caregiver-related factors, social support is a powerful moderator in stroke survivor QOL (Lee et al. 2010). In fact, patients who receive support from family, even patients who are more depressed or less educated, report better QOL than those who do not have social support (Lee et al. 2010). Lack of social support is a predictor of lower emotional QOL even among stroke survivors who are more independent in ADL (Kruithof et al. 2013). Taylor-Piliae et al. (2013) found that social support predicts better physical functioning, greater vitality and less depression in stroke patients.

The continuity of stroke rehabilitation after discharge from the rehabilitation hospital was found to influence QOL for both stroke survivors and their caregivers. Among stroke patients, the continuity of rehabilitation was associated with a significant reduction of dependence (Aprile et al. 2008, Shyu et al. 2009).

Another variable that moderates the relationship between predictors and outcomes for the stroke survivor-caregiver dyad is caregiver preparation. Ostwald et al. (2009b) and Grant et al. (2013) have shown that low preparedness is a 
significant predictor of caregiver stress, as well as a predictor of negative mood and depression among caregivers.

\section{The study}

\section{Aims}

The aim of this study is to describe stroke survivor-caregiver dyad's QOL at discharge from rehabilitation hospital and at 3, 6, 9 and 12 months later and to examine how QOL changes over time by looking at the effect of the preexisting situation prior to the stroke, the new situation mediation poststroke and any moderation caused by environmental- and caregiver-related variables.

\section{Hypotheses}

Three hypotheses were generated from the conceptual framework:

- Dyadic characteristics (pre-existing situation prior to the stroke) predict stroke survivor-caregiver dyad's QOL (dyadic outcomes);

- Stroke-related variables and caregiving-related variables (the new situation mediation poststroke) mediate the relationship between the dyadic characteristics (preexisting situation prior to the stroke) and stroke survivor-caregiver QOL (dyadic outcomes);

- Environmental- and caregiver-related variables (situation moderators) moderate the relationship among dyadic characteristics (pre-existing situation prior to the stroke), stroke-related variables and caregiving-related variables (new situation mediation poststroke) and stroke survivor-caregiver QOL (dyadic outcomes).

\section{Design/methodology}

A longitudinal design will be used. As described above, variables in the conceptual framework, (e.g. caregiver burden) are likely to vary over time due to changes caused by the stroke survivor's recovery and skills acquired in caregiving. For these reasons, a longitudinal design is appropriate.

\section{Sample/participants}

A convenience sample of stroke survivor-caregiver dyads will be enrolled. Stroke survivor inclusion criteria are: (1) a diagnosis of stroke; (2) discharge from a rehabilitation hospital; and (3) the willingness to provide written consent to participate in the study. Stroke survivors will be excluded if they have: (1) severe and pre-existing psychiatric or physical/motor deficits (e.g. dementia, Multiple Sclerosis); (2) a previous stroke, aphasia or reduced level of consciousness; (3) a cancer (either terminal or under active treatment); (4) a severe organ failure condition that is known to be associated with poor QOL. Inclusion criteria for stroke caregivers are the following: (1) being identified as the main caregiver by the patient without being paid; (2) the stroke survivor's agreement to participate in the study; and (3) the willingness to provide written consent to participate. If one member of the dyad cannot be included in the study, both stroke survivor and caregiver will be excluded.

\section{Sample size}

Because we will examine the model shown in Figure 1 with structural equation model technique, a large sample is required. In accordance with Kline (2011), a sample of minimum 200 patient-caregiver dyads will be necessary.

\section{Data collection}

Intervals of measurement have been planned consistent with the international literature as measured at baseline (time 0 , coinciding with the discharge of patients from rehabilitation hospitals) and then 3, 6, 9 and 12 months later (Godwin et al. 2013b, Mayo et al. 2013).

Guided by the conceptual framework, several instruments will be used to collect the data about pre-existing situation prior to stroke, the new situation mediation poststroke, the situation moderators and dyadic outcomes (Table 1). The pre-existing situation prior to stroke has been operationalized as dyad characteristics and will be measured using two socio-demographic questionnaires developed to collect dyad data such as age, gender, marital status, employment, education, income, living conditions and family situation, both for the patient and the caregiver, the Mutuality Scale (Archbold et al. 1990) and the Modified Charlson Comorbidity Index (Goldstein et al. 2004).

The Mutuality Scale (MS) (Archbold et al. 1990) consists of 15 items that measure mutuality defined as the positive quality of the relationship between a caregiver and a care receiver. There are two versions of the scale: the patient version and the caregiver version. Each item uses a 5-point Likert scale from 0 ('nothing')-4 ('very much'). The total scale score ranges from 0-60. Higher scores indicate higher mutuality. The MS has been used in several studies (Tanji et al. 2008, Ostwald et al. 2009b) and has demonstrated adequate validity and reliability (Archbold et al. 1990).

The Modified Charlson Comorbidity Index (MCCI) (Goldstein et al. 2004) assesses the presence of 16 comorbid conditions, which are weighted with a score from 1 (e.g. diabetes without complications)-6 (e.g. cancer or AIDS). 
The total score ranges from $0-31$, with higher scores meaning higher comorbidity. This index has been used extensively in stroke studies (Bushnell et al. 2008) and, compared with other comorbidity indices, has been found to be more accurate in predicting functional outcomes after a stroke (Tessier et al. 2008).

The new situation mediation poststroke has been operationalized as stroke-related variables and caregiving-related variables. Stroke-related variables will be evaluated using a clinical questionnaire, the Barthel Index (Mahoney \& Barthel 1965), the Hospital Anxiety and Depression Scale (HADS) (Zigmond \& Snaith 1983) and the living and caring questionnaire. Caregiving-related variables will be measured with the HADS, the Caregiver Burden Inventory (CBI) (Novak \& Guest 1989) and relevant questions embedded in the socio-demographic questionnaire that record expenses for care borne by the caregiver and hours and duration of caregiving.

The clinical questionnaire and the living and caring questionnaire are two investigator-developed tools that will be used to collect clinical data about type and site of stroke, healthcare costs and complications (e.g. falls).

The Barthel Index (BI) (Mahoney \& Barthel 1965) is a widely used valid and reliable scale that measures physical functioning in 10 activities of daily living (ADL) (e.g. mobility). Score ranges from $0-100$, where a higher score means greater independence.

The HADS (Zigmond \& Snaith 1983) is a 14-item tool that investigates anxiety and depression (7 items for each). Each subscale score ranges from 0-21: a higher score corresponds to higher levels of anxiety and depression. The HADS is widely used on stroke patients (Sagen et al. 2010). Validity and reliability of the HADS are adequate (Bjelland et al. 2002).

The Caregiver Burden Inventory (CBI) (Novak \& Guest 1989) assesses the caregiver's burden. It consists of 24 items, which use a 4-point Likert scale. Higher scores indicate a greater burden (Novak \& Guest 1989). Novak \& Guest (Novak \& Guest 1989) reported Cronbach's alphas for subscales ranging from 0.76-0.96. The CBI has been also used on Italian caregivers (D'Amelio et al. 2009, Luchetti et al. 2009).

The situation moderators have been operationalized as environmental- and caregiver-related variables and will be evaluated with the Multidimensional Scale of Perceived Social Support (MSPSS) (Zimet et al. 1990), the Caregiving Preparedness Scale (CPS) (Archbold et al. 1990) and with information collected with the socio-demographic questionnaire about continuity of stroke rehabilitation.

The MSPSS (Zimet et al. 1990) measures the perceived support received from family members, friends and signifi- cant persons. It consists of 12 items, which use a 7-point Likert scale from 'strongly disagree' to 'strongly agree'. The score ranges from $0-84$ with higher score meaning the perception of greater social support. This scale has been used in several studies on caregiving (Yu et al. 2013) and has adequate internal consistency reliability. It has been used also in an Italian study resulting in adequate validity and reliability (Cicero et al. 2009).

The Caregiver Preparedness Scale (CPS) (Archbold et al. 1990) measures the preparedness of the caregiver in caregiving activities (e.g. physical care). It is composed of eight items, which use a 5-point Likert scale from 'not at all prepared' to 'very well prepared'. The score ranges from 0-40: higher score means a better preparedness for caregiving. The CPS has been used in several studies and in stroke caregivers (Ostwald et al. 2009a, Owolabi 2010) and has adequate validity and reliability (Archbold et al. 1990).

The dyadic outcomes have been operationalized as the QOL for the stroke survivor-caregiver dyads and will be measured by: the Stroke Impact Scale 3.0 (SIS 3.0) (Duncan et al. 1999, Vellone et al. 2014), the World Health Organization Quality of Life-Brief (WHOQOL-BRIEF) (WHOQOL Group 1998) and the World Health Organization Quality of Life-Spiritual, Religiousness and Personal Beliefs (WHOQOL-SRPB) (WHOQOL-SRPB Group 2006).

The SIS 3.0 (Duncan et al. 2003, Vellone et al. 2014) is a valid and reliable multidimensional and disease-specific instrument to measure QOL in patients with stroke. It is composed of 59 items, which use a 5 -point Likert scale. The SIS 3.0 also has a $0-100$ VAS item that measures the perceived global recovery from stroke. The SIS 3.0 has a standardized score from 0-100, where higher scores mean a better quality of life. This scale will be used only for patients.

The WHOQOL-BRIEF (WHOQOL Group 1998) is a 26item instrument that measures four domains of QOL: physical, psychological, social and environmental. Each item uses a 5-point Likert scale and a standardized score from 0-100 can be computed per each scale with higher scores meaning better QOL. Concurrent validity of the WHOQOL-BRIEF has been demonstrated (WHOQOL Group 1998). The Italian version of the WHOQOL-BRIEF showed adequate validity and reliability (De Girolamo et al. 2000).

The WHOQOL-SRPB (WHOQOL-SRPB Group 2006) consists of 32 questions measuring additional domains of QOL related to spirituality, religion and beliefs. The eight domains are: spiritual connection, meaning and purpose in life, experience of awe and wonder, wholeness and integration, spiritual strength, inner peace, hope and optimism and faith (Giovagnoli et al. 2006). Validity and reliability of this instrument are supportive (Panzini et al. 2011). This 
Table 1 Variables and instruments that will be used to collect the data corresponding to the conceptual framework concepts.

\begin{tabular}{|c|c|c|c|c|c|}
\hline \multirow[b]{2}{*}{$\begin{array}{l}\text { Conceptual framework } \\
\text { concepts }\end{array}$} & \multirow[b]{2}{*}{ Operationalized as: } & \multirow[b]{2}{*}{ Measured by: } & \multicolumn{2}{|c|}{ Individual measures: } & \multirow[b]{2}{*}{$\begin{array}{l}\text { Measured } \\
\text { at (months): }\end{array}$} \\
\hline & & & $\begin{array}{l}\text { Stroke } \\
\text { survivor }\end{array}$ & $\begin{array}{l}\text { Stroke } \\
\text { caregiver }\end{array}$ & \\
\hline \multirow[t]{9}{*}{$\begin{array}{l}\text { Pre-existing situation } \\
\text { prior to stroke }\end{array}$} & $\begin{array}{l}\text { Dyadic characteristics } \\
\text { Stroke survivor }\end{array}$ & & & & \\
\hline & Socio-demographic & Socio-demographic questionnaire & $\mathrm{X}$ & & 0 \\
\hline & Living conditions & Socio-demographic questionnaire & $\mathrm{X}$ & & 0 \\
\hline & Relationship & Mutuality scale & $\mathrm{X}$ & & 0 \\
\hline & $\begin{array}{l}\text { Stroke survivor's } \\
\text { comorbidity }\end{array}$ & $\begin{array}{l}\text { Modified Charlson Comorbidity } \\
\text { Index }\end{array}$ & $\mathrm{X}$ & & 0 \\
\hline & Stroke caregiver & & & & \\
\hline & Socio-demographic & Socio-demographic questionnaire & & $\mathrm{X}$ & 0 \\
\hline & Living conditions & Socio-demographic questionnaire & & $\mathrm{X}$ & 0 \\
\hline & Relationship & Mutuality scale & $\mathrm{X}$ & $\mathrm{X}$ & 0 \\
\hline \multirow{11}{*}{$\begin{array}{l}\text { New situation } \\
\text { mediation poststroke }\end{array}$} & Stroke-related variables & & & & \\
\hline & Type and site of stroke & Clinical questionnaire & $\mathrm{X}$ & & 0 \\
\hline & Physical functioning & Barthel index & $\mathrm{X}$ & & $0,3,6,9,12$ \\
\hline & $\begin{array}{l}\text { Mood state (depression } \\
\text { and anxiety) }\end{array}$ & HADS & $\mathrm{X}$ & & $0,3,6,9,12$ \\
\hline & $\begin{array}{l}\text { Stroke complications } \\
\text { (e.g. falls) }\end{array}$ & Living and caring questionnaire & $\mathrm{X}$ & & $0,3,6,9,12$ \\
\hline & $\begin{array}{l}\text { Caregiving-related } \\
\text { variables }\end{array}$ & & & & \\
\hline & Depression and anxiety & HADS & & $\mathrm{X}$ & $0,3,6,9,12$ \\
\hline & Burden & Caregiving Burden Inventory & & $\mathrm{X}$ & $0,3,6,9,12$ \\
\hline & Time for caregiving & Socio-demographic questionnaire & & $\mathrm{X}$ & $0,3,6,9,12$ \\
\hline & Expenses for care & Socio-demographic questionnaire & & $\mathrm{X}$ & $0,3,6,9,12$ \\
\hline & Caregiving duration & Socio-demographic questionnaire & & $\mathrm{X}$ & $0,3,6,9,12$ \\
\hline \multirow[t]{4}{*}{ Situation moderators } & $\begin{array}{l}\text { Environmental- and } \\
\text { caregiver-related } \\
\text { variables }\end{array}$ & & & & \\
\hline & Social support & MSPSS & & $\mathrm{X}$ & $0,3,6,9,12$ \\
\hline & $\begin{array}{l}\text { Continuity of stroke } \\
\text { rehabilitation }\end{array}$ & Socio-demographic questionnaire & $\mathrm{X}$ & & $0,3,6,9,12$ \\
\hline & Caregiving preparation & Caregiving Preparedness Scale & & $\mathrm{X}$ & $0,3,6,9,12$ \\
\hline \multirow[t]{4}{*}{ Dyadic outcomes } & Quality of life & & & & \\
\hline & Stroke survivor QOL & SIS 3.0 & $\mathrm{X}$ & & $0,3,6,9,12$ \\
\hline & & WHOQOL-Brief & $\mathrm{X}$ & $\mathrm{X}$ & $0,3,6,9,12$ \\
\hline & Stroke caregiver QOL & WHOQOL-SRPB & $\mathrm{X}$ & $\mathrm{X}$ & $0,3,6,9,12$ \\
\hline
\end{tabular}

QOL = Quality of life; HADS = Hospital Anxiety and Depression Scale; MSPSS = Multidimensional Scale of Perceived Social Support; SIS = Stroke Impact Scale; WHOQOL-Brief $=$ World Heart Organization Quality of Life-Brief; WHOQOL-SRPB = World Heart Organization Quality of Life-Spiritual Religious and Persona Beliefs

instrument will be used both for stroke survivors and their caregivers.

Patients and caregivers will be approached for enrolment by trained research assistants at the time of patient discharge from rehabilitation hospitals. After the aims of the study have been explained, patients and caregivers willing to participate will sign the informed consent form and will then be interviewed to collect baseline data. In addition, patients' medical records will be reviewed to collect the clinical variables considered in the study (e.g. type and site of stroke). As it is the intention of the study to examine changes over time, data collection will be repeated at 3, 6 , 9 and 12 months after enrolment in the study.

\section{Data analysis}

Descriptive statistics (mean, standard deviation, median, interquartile range, frequencies) will be used to summarize the socio-demographic and clinical data and the scale scores. Pearson and Spearman correlations will be used to 
identify which variables will be correlated with dyad QOL. Multiple linear regression will also be used to identify predictors of the QOL for stroke survivor-caregiver dyads. The actor-partner interdependence model (APIM) will be used to analyse the dyadic data, as this approach allows investigators to evaluate the influence of partners on each other (Ridker et al. 2000). In APIM, the actor effect is the influence of a person's emotions on himself or herself (e.g. the effect of depression on QOL). The partner effect is the impact of the person's emotions on his or her partner (e.g. the effect of depression in the person on the partner's QOL).The APIM will be used as the dyadic analytical procedure to test how some variables in stroke survivors (e.g. depression) will affect the same variables in their caregivers. Structural equation modelling procedures will be used to test the full model outlined in Figure 1. Specifically, both cross-lagged and growth curve models will be used to examine changes in the study variables, its predictors and outcomes. Multi-group analysis will be used to test the effect of moderators (e.g. social support in dyads with high and low QOL) (Baron \& Kenny 1986).

\section{Ethical considerations}

The study has been approved by the ethical committee of the study institution in January 2014 and is in keeping with the Declaration of Helsinki. Stroke survivor-caregiver dyads will be enrolled on voluntary basis. Before data collection, all study participants will receive information about the study and that their data will be confidential and will be stored in a safe place. The signed informed consent will be obtained by both members of the dyads before proceeding with data collection. Participants will be guaranteed that study results will be published in aggregated form, not allowing the identification of participants. Also, patients and caregivers will be informed that they will have the right to withdraw from the study whenever they want. Research assistants will be trained to respect patients and caregiver time during data collection; thus, if they see that patients and caregivers become tired during data collection, they will offer a pause.

\section{Validity and reliability/rigour}

We will use for the study instruments that have been already tested for validity and reliability. For the tools developed by the research team, such as the socio-demographic questionnaires for patient and caregiver, the clinical questionnaire and the living and caring questionnaire, their content validity has been evaluated by a group of experts. For these tools, we will test also their inter-rater reliability.

\section{Discussion}

This study will provide a description of stroke survivorcaregiver dyad QOL within the first year after a stroke including patterns of QOL over time. The study will also identify predictors, mediators and moderators of QOL for stroke survivor-caregivers dyads as defined in the conceptual framework developed for this study. The longitudinal approach is a powerful method that will examine how the independent variables and dyad outcomes change over time.

The conceptual framework introduced in this paper for examining QOL in both stroke survivors and their caregivers has the potential to provide important information pertinent to the care of stroke survivor-caregiver dyad across the stroke trajectory. Findings are expected to inform clinical practice by identifying the predictors of dyad QOL that are present in the pre-existing situation prior to stroke and the new situation poststroke. Understanding how environmental-related variables moderate dyadic QOL will allow providers to implement a plan of care focused on the needs of the stroke survivor-caregiver dyad.

In addition, this study has been designed with a conceptual framework that can be used by rehabilitation nurses to promote dyadic QOL. Moreover, the results of this study will potentially have important implications for caregiver education including ensuring adequate social support. Understanding the relationship of stroke-related variables such as the type and site of stroke, physical functioning and stroke complications together with caregiver-related variables such as burden, expenses for care and caregiving duration can help prepare caregivers. Nurses play an important role in assessing the support systems available to stroke survivors. Understanding the complexity of the dyadic relationship can help to develop a plan of care and effective recovery strategy that will deal positively with the negative effects of stroke and reinforce the dyad relationship.

Finally, this study is expected to provide much needed evidence to make institutions aware of the potential difficulties experienced by stroke survivors and their caregivers. If the hypotheses are supported, the implications for transitions in care include strengthening the network of continuity of care between rehabilitation facilities and homecare to ensure that stroke survivor-caregiver dyads have adequate emotional and tangible support throughout the recovery period.

\section{Limitations}

As this study will be conducted in Italy, the results should be generalized with caution in other countries due to potential cultural differences. Also, this study will be conducted 
in community settings after patients are discharged home, hence results cannot be generalized to the acute or the rehabilitation phases of the stroke during hospitalization.

This study will use a longitudinal design, which means that patient and caregiver dropout could be another potential limitation. To prevent dropout and to minimize inconvenience for patients and caregivers, all data collection after the baseline will be carried out at the home of the patient and caregiver.

\section{Conclusion}

Because of the ageing of the population, more people in the future will be affected by stroke. This increase in stroke prevalence and incidence represents a burden for the healthcare system, but also a burden for caregivers, who will have the responsibility of caring for the patient when he or she is at home. The dyadic approach guided by a specific conceptual framework developed in this study represents an opportunity to consider the stroke not only as a patient event but also as a dyadic event for patients and their caregivers.

\section{Funding}

This project was supported by the Centre of Excellence for Nursing Scholarship, Rome, Italy.

\section{Conflict of interest}

The authors declare that they have no conflict of interest.

\section{Author contributions}

All authors have agreed on the final version and meet at least one of the following criteria [recommended by the ICMJE (http://www.icmje.org/ethical_1author.html)]:

- they have made substantial contributions to conception and design, acquisition of data, or analysis and interpretation of data;

- have been instrumental in drafting the article or revising it critically for important intellectual content.

\section{References}

Aprile I., Di Stasio E., Romitelli F., Lancellotti S., Caliandro P., Tonali P., Gilardi A. \& Padua L. (2008) Effects of rehabilitation on quality of life in patients with chronic stroke. Brain Injury 22, 451-456.

Archbold P.G., Stewart B.J., Greenlick M.R. \& Harvath T. (1990) Mutuality and preparedness as predictors of caregiver role strain. Research in Nursing and Health 13, 375-384.
Baron R.M. \& Kenny D.A. (1986) The moderator-mediator variable distinction in social psychological research: conceptual, strategic and statistical considerations. Journal of Personality and Social Psychology 51, 1173-1182.

Batchelor F., Hill K., Mackintosh S. \& Said C. (2010) What works in falls prevention after stroke?: a systematic review and metaanalysis. Stroke 41, 1715-1722.

Baumann M., Lurbe K., Leandro M.E. \& Chau N. (2012) Life satisfaction of two-year post-stroke survivors: effects of socioeconomic factors, motor impairment, Newcastle stroke-specific quality of life measure and World Health Organization quality of life: bref of informal caregivers in Luxembourg and a rural area in Portugal. Cerebrovascular Diseases 33, 219-230.

Bjelland I., Dahl A.A., Haug T.T. \& Neckelmann D. (2002) The validity of the Hospital Anxiety and Depression Scale. An updated literature review. Journal of Psychosomatic Research 52, 69-77.

Brajkovic L., Godan A. \& Godan L. (2009) Quality of life after stroke in old age: comparison of persons living in nursing home and those living in their own home. Croatian Medical Journal 50, 182-188.

Bushnell C.D., Lee J., Duncan P.W., Newby L.K. \& Goldstein L.B. (2008) Impact of comorbidities on ischemic stroke outcomes in women. Stroke 39, 2138-2140.

Cadilhac D.A., Dewey H.M., Vos T., Carter R. \& Thrift A.G. (2010) The health loss from ischemic stroke and intracerebral hemorrhage: evidence from the North East Melbourne Stroke Incidence Study (NEMESIS). Health and Quality of Life Outcomes 8, 49.

Carod-Artal F.J. (2012) Determining quality of life in stroke survivors. Expert Review of Pharmacoeconomics \& Outcomes Research 12, 199-211.

Carod-Artal F.J., Ferreira Coral L., Trizotto D.S. \& Menezes Moreira C. (2009) Burden and perceived health status among caregivers of stroke patients. Cerebrovascular Diseases 28, 472-480.

Cecil R., Thompson K., Parahoo K. \& McCaughan E. (2013) Towards an understanding of the lives of families affected by stroke: a qualitative study of home carers. Journal of Advanced Nursing 69, 1761-1770.

Chen R.L., Balami J.S., Esiri M.M., Chen L.K. \& Buchan A.M. (2010) Ischemic stroke in the elderly: an overview of evidence. Nature Reviews. Neurology 6, 256-265.

Cicero V., Lo Coco G., Gullo S. \& Lo Verso G. (2009) The role of attachment dimensions and perceived social support in predicting adjustment to cancer. Psycho-Oncology 18, 1045-1052.

D’Amelio M., Terruso V., Palmeri B., Di Benedetto N., Famoso G., Cottone P., Aridon P., Ragonese P. \& Savettieri G. (2009) Predictors of caregiver burden in partners of patients with Parkinson's disease. Neurological Sciences 30, 171-174.

D’Aniello G.E., Scarpina F., Mauro A., Mori I., Castelnuovo G., Bigoni M., Baudo S. \& Molinari E. (2014) Characteristics of anxiety and psychological well-being in chronic post-stroke patients. Journal of the Neurological Sciences 338, 191-196.

Dayapoglu N. \& Tan M. (2010) Quality of life in stroke patients. Neurology India 58, 697-701.

De Girolamo G., Rucci P., Scocco P., Becchi A., Coppa F., D’Addario A., Daru E., De Leo D., Galassi L., Mangelli L., Marson C., Neri G. \& Soldani L. (2000) Quality of life assessment: validation of the Italian version of the WHOQOLBrief. Epidemiologia e Psichiatria Sociale 9, 45-55. 
Delcourt C., Hackett M., Wu Y., Huang Y., Wang J., Heeley E., Wong L., Sun J., Li Q., Wei J.W., Liu M., Li Z., Wu L., Cheng Y., Huang Q., Xu E., Yang Q., Lu C., Anderson C.S. \& China Q.I. (2011) Determinants of quality of life after stroke in China: the ChinaQUEST (QUality Evaluation of Stroke care and Treatment) study. Stroke 42, 433-438.

Duncan P.W., Wallace D., Lai S.M., Johnson D., Embretson S. \& Laster L.J. (1999) The stroke impact scale version 2.0. Evaluation of reliability, validity and sensitivity to change. Stroke 30, 2131-2140.

Duncan P.W., Bode R.K., Min Lai S. \& Perera S. (2003) Rasch analysis of a new stroke-specific outcome scale: the Stroke Impact Scale. Archives of Physical Medicine and Rehabilitation 84, 950-963.

Ellis C., Grubaugh A.L. \& Egede L.E. (2013) Factors associated with SF-12 physical and mental health quality of life scores in adults with stroke. Journal of Stroke and Cerebrovascular Diseases 22, 309-317.

European Registers of Stroke I., Heuschmann P.U., Di Carlo A., Bejot Y., Rastenyte D., Ryglewicz D., Sarti C., Torrent M. \& Wolfe C.D. (2009) Incidence of stroke in Europe at the beginning of the 21st century. Stroke 40, 1557-1563.

Feigin V.L., Forouzanfar M.H., Krishnamurthi R., Mensah G.A., Connor M., Bennett D.A., Moran A.E., Sacco R.L., Anderson L., Truelsen T., O’Donnell M., Venketasubramanian N., BarkerCollo S., Lawes C.M., Wang W., Shinohara Y., Witt E., Ezzati M., Naghavi M., Murray C., Global Burden of Diseases I., Risk Factors S. \& the G.B.D.S.E.G. (2014) Global and regional burden of stroke during 1990-2010: findings from the Global Burden of Disease Study 2010. Lancet 383, 245-254.

Garcia-Perez L., Linertova R., Lorenzo-Riera A., Vazquez-Diaz J.R., Duque-Gonzalez B. \& Sarria-Santamera A. (2011) Risk factors for hospital readmissions in elderly patients: a systematic review. QJM An International Journal of Medicine 104, 639-651.

Giovagnoli A.R., Meneses R.F. \& da Silva A.M. (2006) The contribution of spirituality to quality of life in focal epilepsy. Epilepsy \& Behavior 9, 133-139.

Go A.S., Mozaffarian D., Roger V.L., Benjamin E.J., Berry J.D., Blaha M.J., Dai S., Ford E.S., Fox C.S., Franco S., Fullerton H.J., Gillespie C., Hailpern S.M., Heit J.A., Howard V.J., Huffman M.D., Judd S.E., Kissela B.M., Kittner S.J., Lackland D.T., Lichtman J.H., Lisabeth L.D., Mackey R.H., Magid D.J., Marcus G.M., Marelli A., Matchar D.B., McGuire D.K., Mohler E.R. 3rd, Moy C.S., Mussolino M.E., Neumar R.W., Nichol G., Pandey D.K., Paynter N.P., Reeves M.J., Sorlie P.D., Stein J., Towfighi A., Turan T.N., Virani S.S., Wong N.D., Woo D., Turner M.B., American Heart Association Statistics C. \& Stroke Statistics S. (2014) Heart disease and stroke statistics-2014 update: a report from the American Heart Association. Circulation 129, e28-e292.

Godwin K.M., Ostwald S.K., Cron S.G. \& Wasserman J. (2013a) Long-term health-related quality of life of stroke survivors and their spousal caregivers. Journal of Neuroscience Nursing 45, 147-154.

Godwin K.M., Swank P.R., Vaeth P. \& Ostwald S.K. (2013b) The longitudinal and dyadic effects of mutuality on perceived stress for stroke survivors and their spousal caregivers. Aging and Mental Health 17, 423-431.
Goldstein L.B., Samsa G.P., Matchar D.B. \& Horner R.D. (2004) Charlson Index comorbidity adjustment for ischemic stroke outcome studies. Stroke 35, 1941-1945.

Grant M., Sun V., Fujinami R., Sidhu R., Otis-Green S., Juarez G., Klein L. \& Ferrell B. (2013) Family caregiver burden, skills preparedness and quality of life in non-small cell lung cancer. Oncology Nursing Forum 40, 337-346.

Green T.L. \& King K.M. (2010) Functional and psychosocial outcomes 1 year after mild stroke. Journal of Stroke and Cerebrovascular Diseases 19, 10-16.

Icks A., Claessen H., Morbach S., Glaeske G. \& Hoffmann F. (2012) Time-dependent impact of diabetes on mortality in patients with stroke: survival up to 5 years in a health insurance population cohort in Germany. Diabetes Care 35, 1868-1875.

Kline R. (2011) Principles and Practice of Structural Equation Modeling, 3rd edn. The Guilford Press, New York.

Klinedinst N.J., Gebhardt M.C., Aycock D.M., Nichols-Larsen D.S., Uswatte G., Wolf S.L. \& Clark P.C. (2009) Caregiver characteristics predict stroke survivor quality of life at 4 months and 1 year. Research in Nursing and Health 32, 592-605.

Korpershoek C., van der Bijl J. \& Hafsteinsdottir T.B. (2011) Selfefficacy and its influence on recovery of patients with stroke: a systematic review. Journal of Advanced Nursing 67, 1876-1894.

Kouwenhoven S.E., Kirkevold M., Engedal K. \& Kim H.S. (2011) Depression in acute stroke: prevalence, dominant symptoms and associated factors. A systematic literature review. Disability and Rehabilitation 33, 539-556.

Kronish I.M., Edmondson D., Goldfinger J.Z., Fei K. \& Horowitz C.R. (2012) Posttraumatic stress disorder and adherence to medications in survivors of strokes and transient ischemic attacks. Stroke 43, 2192-2197.

Kruithof W.J., van Mierlo M.L., Visser-Meily J.M., van Heugten C.M. \& Post M.W. (2013) Associations between social support and stroke survivors' health-related quality of life-a systematic review. Patient Education and Counseling 93, 169-176.

Lazarus R.S. \& Folkman S. (1984) Stress, appraisal, and coping. Springer, New Jork.

Lee H.Y., Hwang J.S., Jeng J.S. \& Wang J.D. (2010) Qualityadjusted life expectancy (QALE) and loss of QALE for patients with ischemic stroke and intracerebral hemorrhage: a 13-year follow-up. Stroke 41, 739-744.

Levy J.A., Landerman L.R. \& Davis L.L. (2011) Advances in mediation analysis can facilitate nursing research. Nursing Research 60, 333-339.

Luchetti L., Uhunmwangho E., Dordoni G., Lorido A., Barbieri S., Bolognesi A.G., Gobbi G. \& Franchi F. (2009) The subjective feeling of burden in caregivers of elderly with dementia: how to intervene? Archives of Gerontology and Geriatrics 49(Suppl 1), 153-161.

Lurbe-Puerto K., Leandro M.E. \& Baumann M. (2012) Experiences of caregiving, satisfaction of life and social repercussions among family caregivers, two years post-stroke. Social Work in Health Care 51, 725-742.

Mahoney F.I. \& Barthel D.W. (1965) Functional evaluation: the barthel index. Maryland State Medical Journal 14, 61-65.

Mayo N.E., Scott S.C., Bayley M., Cheung A., Garland J., Jutai J. \& Wood-Dauphinee S. (2013) Modeling health-related quality of life in people recovering from stroke. Quality of Life Research 2013 Dec 19. [Epub ahead of print] DOI: 10.1007/s11136-013-0605-4. 
McCubbin H.I., Sussman M.B. \& Patterson J.M. (1983) Social Stress and the Family: Advances and Developments in Family Stress Theory and Research. Haworth Press, New York.

McPherson C.J., Wilson K.G., Chyurlia L. \& Leclerc C. (2011) The caregiving relationship and quality of life among partners of stroke survivors: a cross-sectional study. Health and Quality of Life Outcomes 9, 29.

Nir Z., Greenberger C. \& Bachner Y.G. (2009) Profile, burden and quality of life of Israeli stroke survivor caregivers: a longitudinal study. Journal of Neuroscience Nursing 41, 92-105.

Novak M. \& Guest C. (1989) Application of a multidimensional caregiver burden inventory. Gerontologist 29, 798-803.

Ostwald S.K., Bernal M.P., Cron S.G. \& Godwin K.M. (2009a) Stress experienced by stroke survivors and spousal caregivers during the first year after discharge from inpatient rehabilitation. Topics in Stroke Rehabilitation 16, 93-104.

Ostwald S.K., Godwin K.M. \& Cron S.G. (2009b) Predictors of life satisfaction in stroke survivors and spousal caregivers after inpatient rehabilitation. Rehabilitation Nursing 34, 160-167, 174; discussion 174 .

Owolabi M.O. (2010) What are the consistent predictors of generic and specific post-stroke health-related quality of life? Cerebrovascular Diseases 29, 105-110.

Panzini R.G., Maganha C., Rocha N.S., Bandeira D.R. \& Fleck M.P. (2011) Brazilian validation of the Quality of Life Instrument/spirituality, religion and personal beliefs. Revista de Saude Publica 45, 153-165.

Perrin P.B., Heesacker M., Hinojosa M.S., Uthe C.E. \& Rittman M.R. (2009) Identifying at-risk, ethnically diverse stroke caregivers for counseling: a longitudinal study of mental health. Rehabilitation Psychology 54, 138-149.

Raju R.S., Sarma P.S. \& Pandian J.D. (2010) Psychosocial problems, quality of life and functional independence among Indian stroke survivors. Stroke 41, 2932-2937.

Ridker P.M., Hennekens C.H., Buring J.E. \& Rifai N. (2000) Creactive protein and other markers of inflammation in the prediction of cardiovascular disease in women. New England Journal of Medicine 342, 836-843.

Rouillard S., De Weerdt W., De Wit L. \& Jelsma J. (2012) Functioning at 6 months post stroke following discharge from inpatient rehabilitation. South African Medical Journal 102, 545-548.

Sagen U., Finset A., Moum T., Morland T., Vik T.G., Nagy T. \& Dammen T. (2010) Early detection of patients at risk for anxiety, depression and apathy after stroke. General Hospital Psychiatry 32, 80-85.

Shyu Y.I., Maa S.H., Chen S.T. \& Chen M.C. (2009) Quality of life among older stroke patients in Taiwan during the first year after discharge. Journal of Clinical Nursing 18, 2320-2328.

Simeone S., Savini S., Cohen M.Z., Alvaro R. \& Vellone E. (2014) The experience of stroke survivors three months after being discharged home: a phenomenological investigation. European Journal of Cardiovascular Nursing 2014 Feb 2. [Epub ahead of print] DOI 10.1177/1474515114522886.

Sreedharan S.E., Unnikrishnan J.P., Amal M.G., Shibi B.S., Sarma S. \& Sylaja P.N. (2013) Employment status, social function decline and caregiver burden among stroke survivors. A South Indian study. Journal of the Neurological Sciences 332, 97-101.
Tanji H., Anderson K.E., Gruber-Baldini A.L., Fishman P.S., Reich S.G., Weiner W.J. \& Shulman L.M. (2008) Mutuality of the marital relationship in Parkinson's disease. Movement Disorders 23, 1843-1849.

Taylor-Piliae R.E., Hepworth J.T. \& Coull B.M. (2013) Predictors of depressive symptoms among community-dwelling stroke survivors. Journal of Cardiovascular Nursing 28, 460-467.

Tessier A., Finch L., Daskalopoulou S.S. \& Mayo N.E. (2008) Validation of the Charlson Comorbidity Index for predicting functional outcome of stroke. Archives of Physical Medicine and Rehabilitation 89, 1276-1283.

Van Puymbroeck M., Hinojosa M.S. \& Rittman M.R. (2008) Influence of sense of coherence on caregiver burden and depressive symptoms at 12 months poststroke. Top Stroke Rehabil 15, 272-282.

Vellone E., Savini S., Fida R., Dickson V.V., Melkus G.D., CarodArtal F.J., Rocco G. \& Alvaro R. (2014) Psychometric Evaluation of the Stroke Impact Scale 3.0. Journal of Cardiovascular Nursing 2014 Apr 1. [Epub ahead of print] DOI 10.1097/JCN.0000000000000145.

Vincent C., Desrosiers J., Landreville P., Demers L. \& group B. (2009) Burden of caregivers of people with stroke: evolution and predictors. Cerebrovascular Diseases 27, 456-464.

Visser-Meily A., Post M., Schepers V. \& Lindeman E. (2005) Spouses' quality of life 1 year after stroke: prediction at the start of clinical rehabilitation. Cerebrovascular Diseases 20, 443-448.

Visser-Meily A., Post M., van de Port I., van Heugten C. \& van den Bos T. (2008) Psychosocial functioning of spouses in the chronic phase after stroke: improvement or deterioration between 1 and 3 years after stroke? Patient Education and Counseling 73, 153-158.

Wagner L.M., Phillips V.L., Hunsaker A.E. \& Forducey P.G. (2009) Falls among community-residing stroke survivors following inpatient rehabilitation: a descriptive analysis of longitudinal data. BMC Geriatrics 9, 46.

Weerdesteyn V., de Niet M., van Duijnhoven H.J. \& Geurts A.C. (2008) Falls in individuals with stroke. Journal of Rehabilitation Research and Development 45, 1195-1213.

White C.L., Mayo N., Hanley J.A. \& Wood-Dauphinee S. (2003) Evolution of the caregiving experience in the initial 2 years following stroke. Research in Nursing and Health 26, 177-189.

WHOQOL Group (1998) Development of the World Health Organization WHOQOL-BREF quality of life assessment. Psychological Medicine 28, 551-558.

WHOQOL-SRPB Group (2006) A cross-cultural study of spirituality, religion and personal beliefs as components of quality of life. Social Science and Medicine 62, 1486-1497.

Yu Y., Hu J., Efird J.T. \& McCoy T.P. (2013) Social support, coping strategies and health-related quality of life among primary caregivers of stroke survivors in China. Journal of Clinical Nursing 22, 2160-2171.

Zigmond A.S. \& Snaith R.P. (1983) The hospital anxiety and depression scale. Acta Psychiatrica Scandinavica 67, 361-370.

Zimet G.D., Powell S.S., Farley G.K., Werkman S. \& Berkoff K.A. (1990) Psychometric characteristics of the Multidimensional Scale of Perceived Social Support. Journal of Personality Assessment 55, 610-617. 
The Journal of Advanced Nursing (JAN) is an international, peer-reviewed, scientific journal. JAN contributes to the advancement of evidence-based nursing, midwifery and health care by disseminating high quality research and scholarship of contemporary relevance and with potential to advance knowledge for practice, education, management or policy. JAN publishes research reviews, original research reports and methodological and theoretical papers.

For further information, please visit $J A N$ on the Wiley Online Library website: www.wileyonlinelibrary.com/journal/jan

\section{Reasons to publish your work in JAN:}

- High-impact forum: the world's most cited nursing journal, with an Impact Factor of 1.527 - ranked 14/101 in the 2012 ISI Journal Citation Reports $\mathbb{C}$ (Nursing (Social Science)).

- Most read nursing journal in the world: over 3 million articles downloaded online per year and accessible in over 10,000 libraries worldwide (including over 3,500 in developing countries with free or low cost access).

- Fast and easy online submission: online submission at http://mc.manuscriptcentral.com/jan.

- Positive publishing experience: rapid double-blind peer review with constructive feedback.

- Rapid online publication in five weeks: average time from final manuscript arriving in production to online publication.

- Online Open: the option to pay to make your article freely and openly accessible to non-subscribers upon publication on Wiley Online Library, as well as the option to deposit the article in your own or your funding agency's preferred archive (e.g. PubMed). 